\title{
Acid Catalyzed Reactions of Substituted Salicylaldehydes with 2-Methylfuran
}

\author{
Alexander V. Butin ${ }^{1} *$, Andrey V. Gutnov ${ }^{2}$, Vladimir T. Abaev², and Gennadij D. Krapivin ${ }^{1}$ \\ ${ }^{1}$ Research Laboratory of Furan Chemistry, Kuban State Technological University, Moskovskaya 2, \\ Krasnodar, 350072, Russia, E-mail: nemol@kubstu.ru \\ ${ }^{2}$ Department of Organic Chemistry, North Ossetian State University, Vatutina 46, Vladikavkaz, \\ 362025, Russia, E-mail: ria@rno.ssc.ac.ru \\ *Author to whom correspondence should be addressed.
}

Received: 21 July 1998/Accepted: 10 August 1998 / Published: 10 March 1999

\begin{abstract}
Data, concerning condensation reactions of salicylaldehydes and 2-methylfuran are generalized. During the course of investigation a sequence of proceeding transformations is established. It is shown that it is possible to obtain 2-hydroxyarylbis(5methylfur-2-yl)methane, benzofuran or oxazulene derivatives selectively by simple changing of the reaction conditions.
\end{abstract}

Keywords: substituted salicylaldehydes, 2-methylfuran, 2-hydroxyaryldyfurylmethanes, benzofuran, disproportion, oxazulene derivatives.

\section{Introduction}

Difurylalkanes have a wide spectrum of practical use as monomers [1-3], modifiers [4,5], crosscoupling reagents $[6,7]$ allowing to lower cost $[8,9]$ and to expand assortment of polymer materials [10] in plastic manufacture. Some compounds of this class are of interest in dye chemistry [11] and copy engineering [12], in synthesis of macrocyclic compounds which are used as metal ions carriers $[13,14]$. The difurylalkanes are of interest for food industry since they were found among numerous

(C) 1999 MDPI. All rights reserved. 
compounds making up coffee aroma [15] and other products [6-18]. Difurylmethane fragment is a component of structure of a number of fungicides [19].

Unfortunately, up to date these compounds have found a little application as synthones in organic synthesis. Structure of difurylalkanes and furan ability to serve as convenient 1,4-diketone equivalent in many chemical reactions $[20,21]$ provide easy access to different classes of carbo- and heterocyclic compounds. Earlier it was reported about the synthesis of carbazole [22, 23], cyclopentenone [24], cynnoline and benzothiazine [25], indole and azaazulenium derivatives [25-27] starting from difurylmethanes.

In this work we wish to present our data on the reaction of substituted salicylaldehydes and 2methylfuran which proceeds with initial formation of 2-hydroxyaryldifurylmethanes and their subsequent transformation into benzofuran and oxazulenium derivatives.

\section{Discussion}

Preliminary results of salicylaldehydes $\mathbf{1}$ interaction with 2-methylfuran $\mathbf{2}$ in the presence of $\mathrm{Mg}\left(\mathrm{ClO}_{4}\right)_{2}$ and $\mathrm{HClO}_{4}[28,29]$ had shown that along with the basic products of reaction - 2hydroxyarylbis(5-methylfur-2-yl)methanes a number of by-products were formed. Especially complex mixtures were formed if perchloric acid was used as a catalyst. The complete separation was achieved by column chromatography only. The products structures and transformations sequence are shown on Scheme 1.

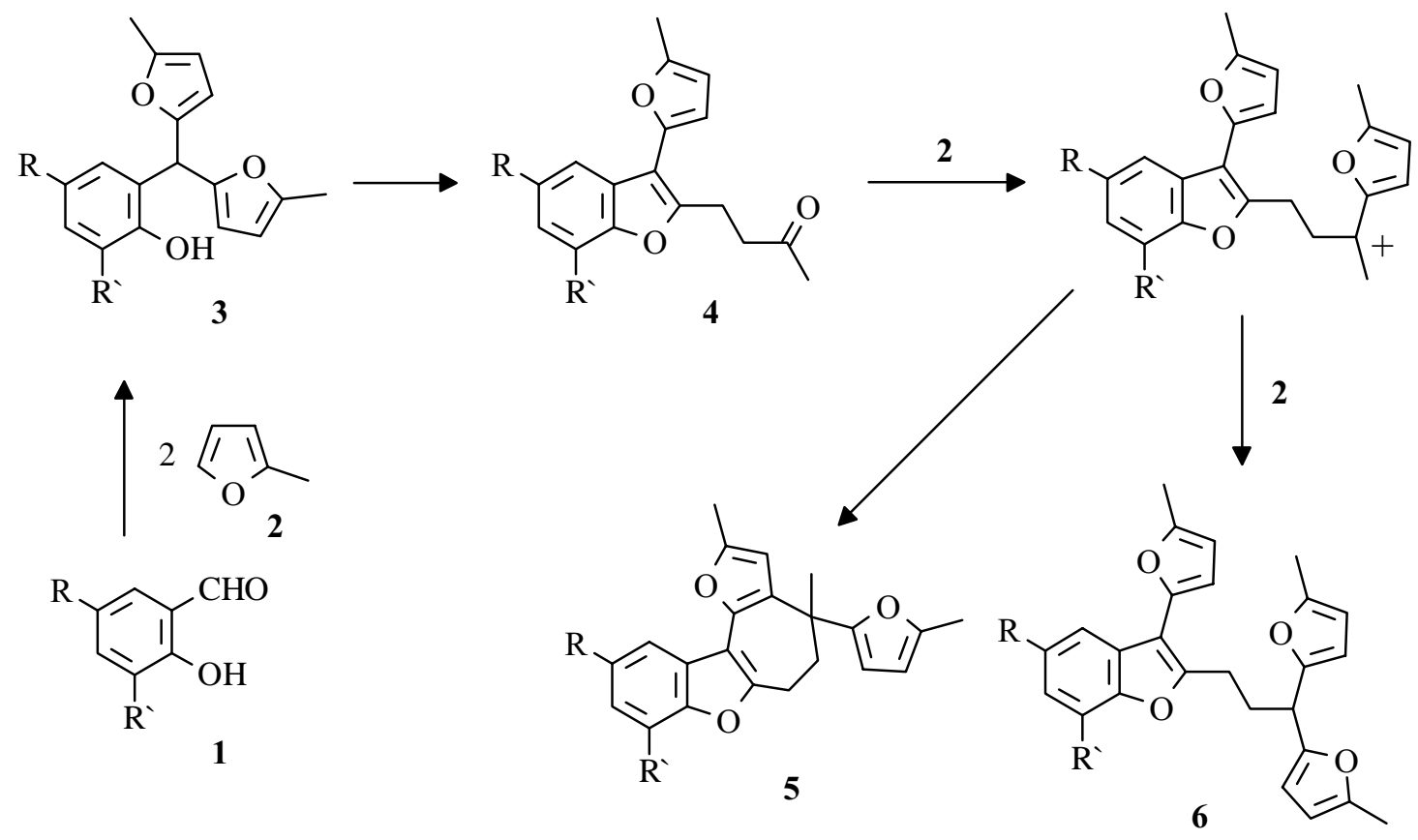

Scheme 1. 
Earlier it has been reported [30] about selective interaction of the reagents $\mathbf{1}$ and $\mathbf{2}$ in dioxane in the presence of macroporous highly acid ion-exchange resin Amberlyst-15 with formation of compounds 3. From our experience this catalyst does not allow to complete the reaction without subsequent transformations. Thus, the extension of reaction time results in increase of benzofuran derivatives 4 amount, whereas at small duration of reaction the conversion of initial aldehydes $\mathbf{1}$ is low.

In the course of our work we have found that phenylboric as well as boric acid and boric anhydride are effective in selective transformation 1 into aryldifurylmethanes $\mathbf{3}$ [31]. The reaction is very selective, since only salicylaldehydes are involved due to intermediate formation of a chelate complex of aldehyde with boric acid (Scheme 2).

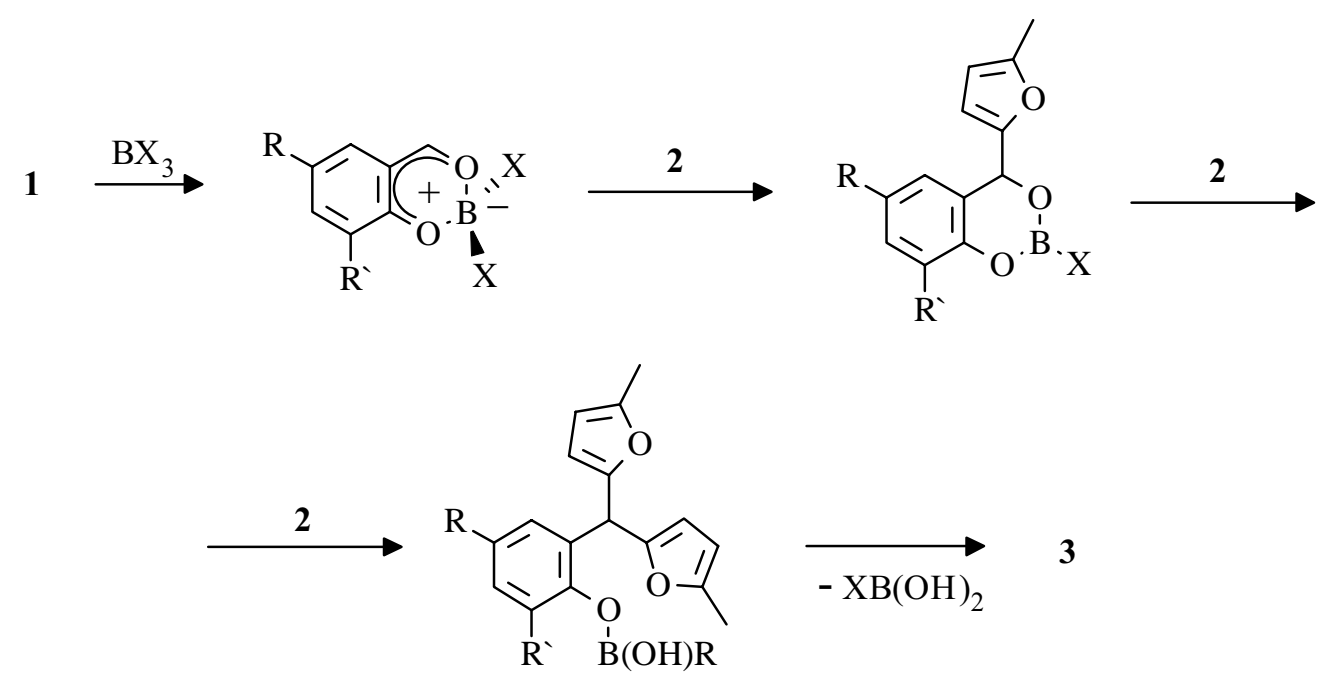

Scheme 2. $\mathrm{X}=\mathrm{Ph}, \mathrm{OH}$.

Having advantage in terms of complete absence of tar and by-products in reaction mixture as compared with a perchloric acid, boric acid derivatives have, from another hand, essential drawback high sensitivity to substituent effects. Satisfactory conversion was reached only in the case of aldehydes 1 bearing withdrawing substituents, while the conversion of salicylaldehyde was $5 \%$ only, and the aldehydes with donor substituents failed to react at all.

Trimethylchlorosilane [31] was recognized as another effective catalyst for mentioned reaction. As it is supposed, the first stage of transformation is a coordination of silicon with carbonyl group of aldehyde in view of high durability of Si-O bond. Formed arylfurylcarbenium ion is electrophilic enough to attack furan ring through the common electrophilic substitution mechanism. 
<smiles>[R]c1cc([R])c(O)c(C([CH]OC)O[Na])c1</smiles><smiles></smiles>

\section{Scheme 3.}

In our opinion, $\mathrm{Me}_{3} \mathrm{SiCl}$ is the catalyst of choice for synthesis of compounds 3 since the process is simple, the side reactions are minimized, the yields of 2-hydroxyaryldifurylmethanes $\mathbf{3}$ are high. It can be used for synthesis with various benzaldehydes.

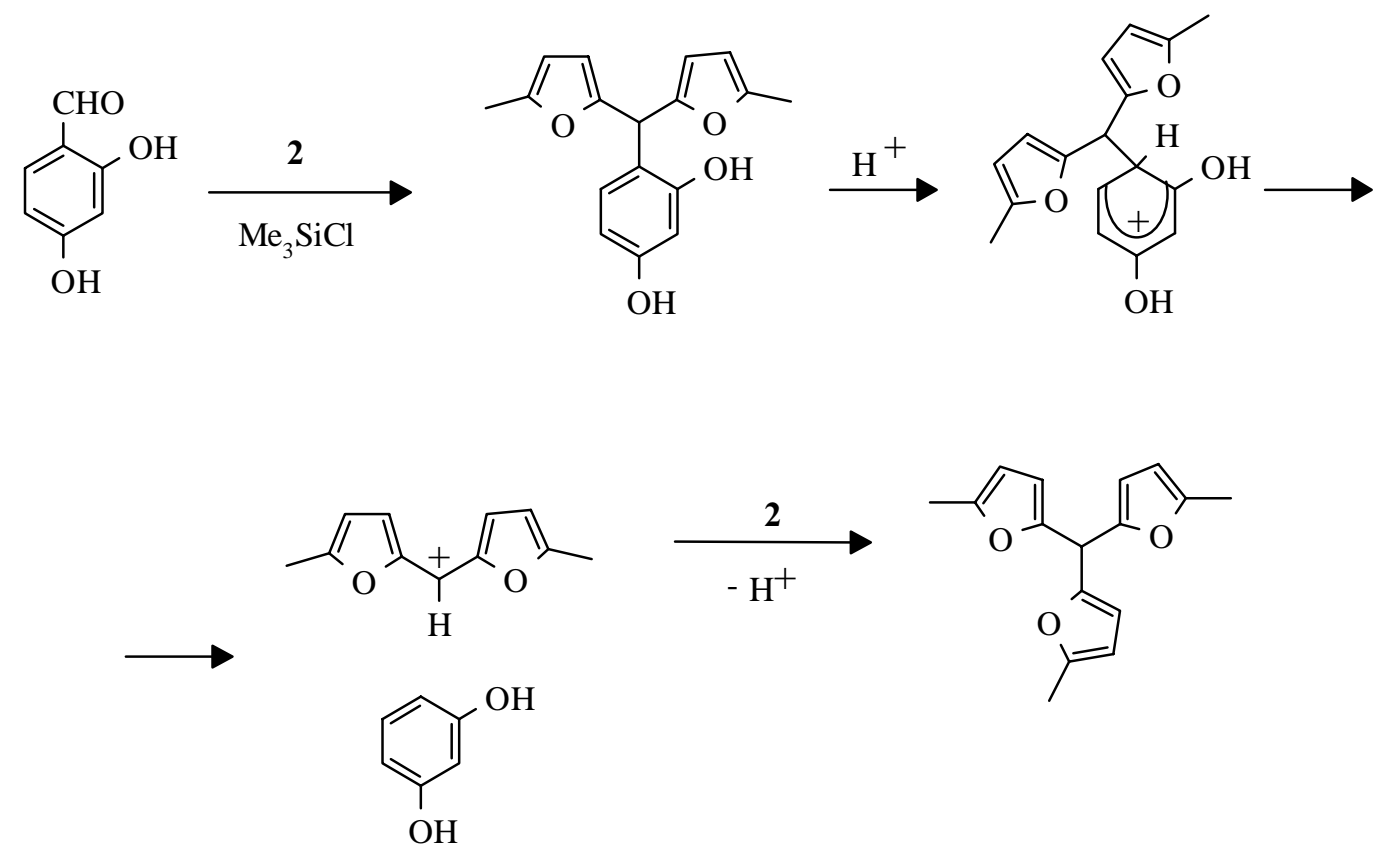

\section{Scheme 4.}

However, attempts to apply $\mathrm{HClO}_{4}$ or $\mathrm{Me}_{3} \mathrm{SiCl}$ in 2,4-dihydroxybenzaldehyde and 2-methylfuran condensation failed. From this reaction tris(5-methylfur-2-yl)methane was isolated with a high yield (Scheme 4). Apparently, the transformations which are similar to described for 2,4dimetoxyphenylbis(5-methylfur-2-yl)methane [32,33] take place in this case. 
It is supposed that at the first stage initially formed 2,4-dihydroxyphenylbis(5-methylfur-2yl)methane undergoes protonation by $\mathrm{HCl}$, which is formed during the reaction, and subsequent ipsosubstitution leading to resorcinole. Fission of $\sigma$-complex results in more stable difurylmethane cation, which quickly reacts with 2-methylfuran giving trifurylmethane. The reaction with 2-hydroxy-1naphtoic aldehyde proceeds similarly.

The selective transformation of compounds 3 into benzofuran derivatives 4 occurs in ethanole saturated with $\mathrm{HCl}$ giving minimum tarification and high yields of the reaction products (Scheme 5) [34].

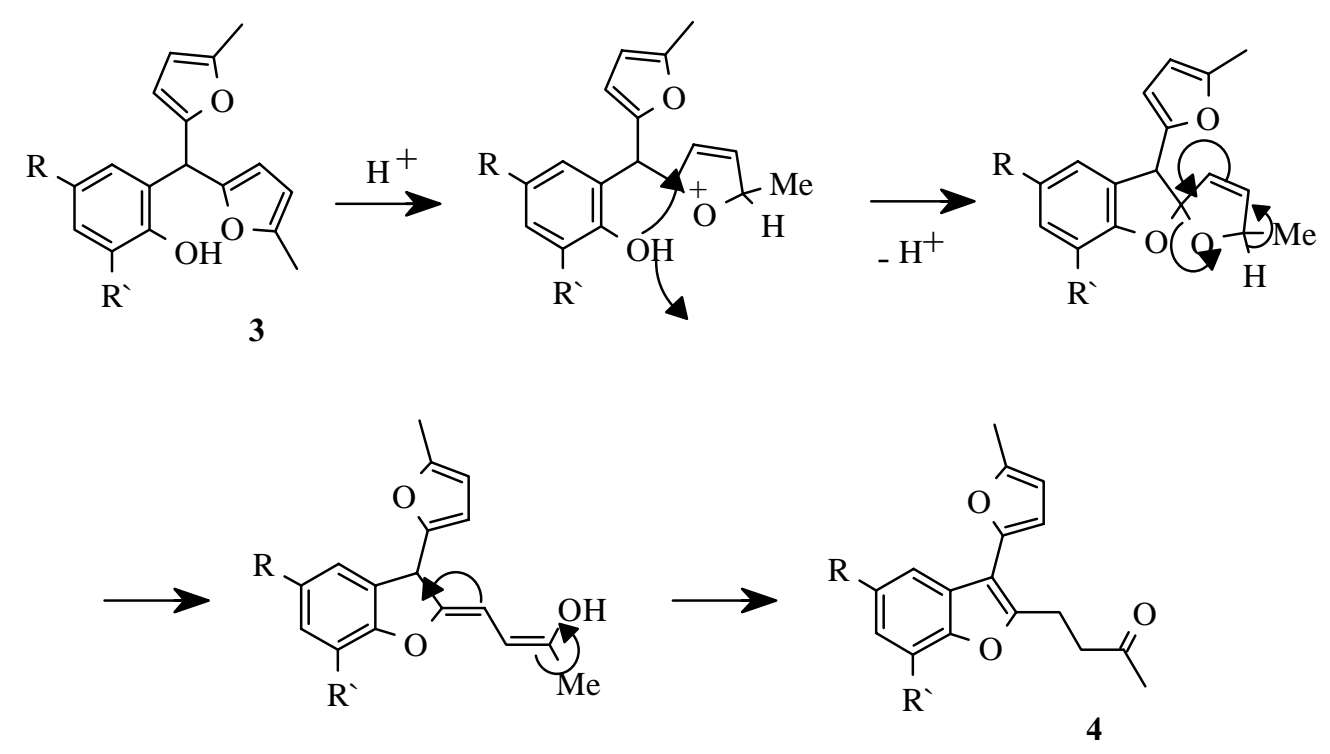

Scheme 5.
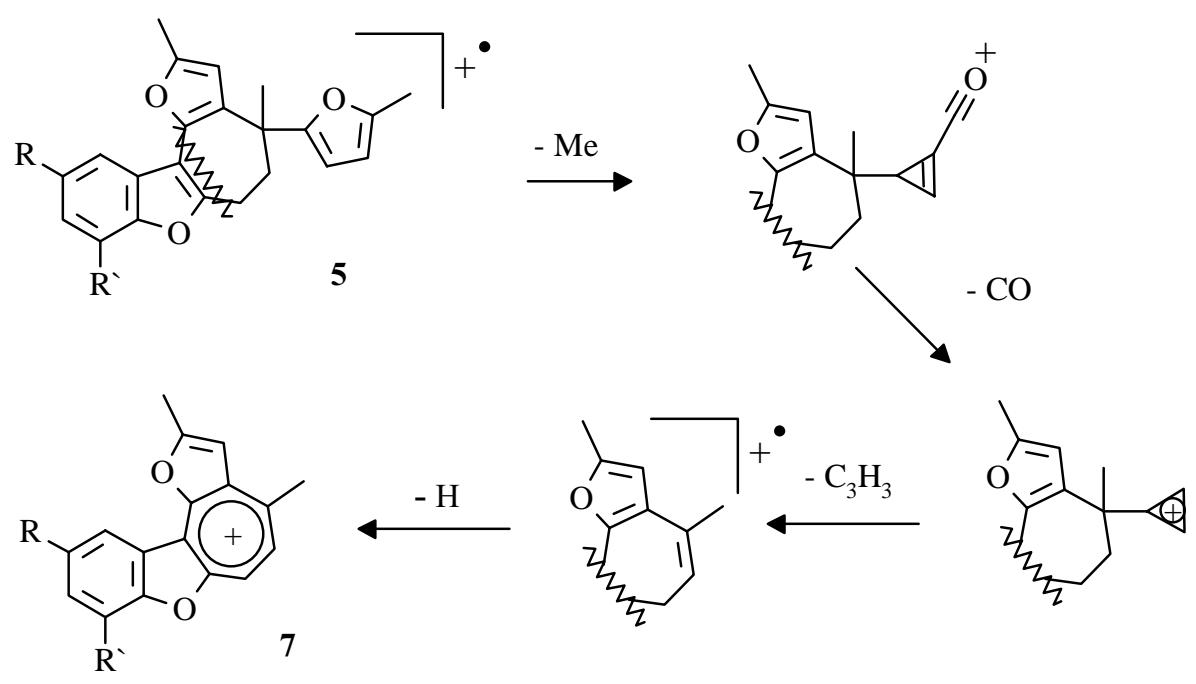

Scheme 6. 
Moreover, under these conditions benzofurans $\mathbf{4}$ can be obtained in one-pot procedure directly from the salicylaldehyde $\mathbf{1}$ and 2-methylfuran 2.

In mass-spectra of compounds $\mathbf{5}$ occurrence of stable cations $\mathbf{7}$, formed in well-known step by step destruction of furan ring (Scheme 6) [29], were observed.

In further studies it was shown that the appropriate benzo[b]furo[2,3-h]-1-oxazulenium salts 7 can be obtained preparatively by treatment of 2-hydroaryldifurylmethanes 3 , benzofurans 4 or compounds $\mathbf{5}$, respectively, with tritylperchlorate [35]. The isolation of 5-methylfur-2-yltriphenylmethane from the reaction mixture allowed to suppose that the transformation of pentacyclic compound $\mathbf{5}$ into perchlorate $\mathbf{7}$ had occured via sylvan elimination by tritylperchlorate and subsequent aromatization of formed cycloheptatrienyl derivative $\mathbf{8}$ (Scheme 7).
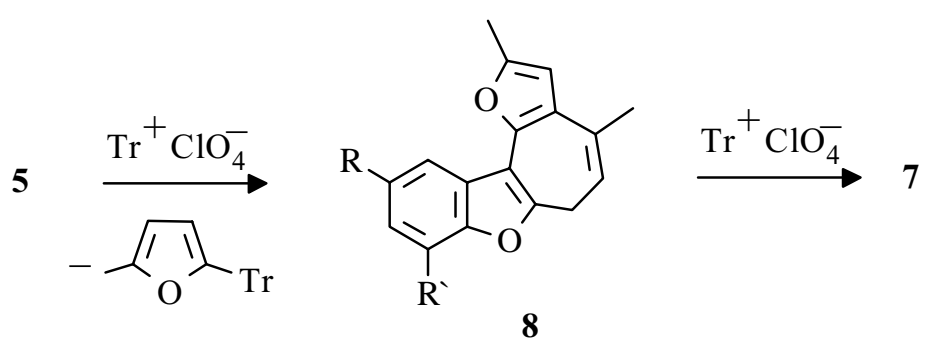

\section{Scheme 7.}

Formation of salts $\mathbf{7}$ from the benzofuran derivatives $\mathbf{4}$, in our opinion, goes via consecutive stages of the intramolecular cyclization of carbonyl group at $\beta$-position of furan cycle, acid catalyzed elimination of triphenylmethanole, resulting in compounds $\mathbf{8}$, with further aromatisation by «hydrideion abstraction» (Scheme 8).

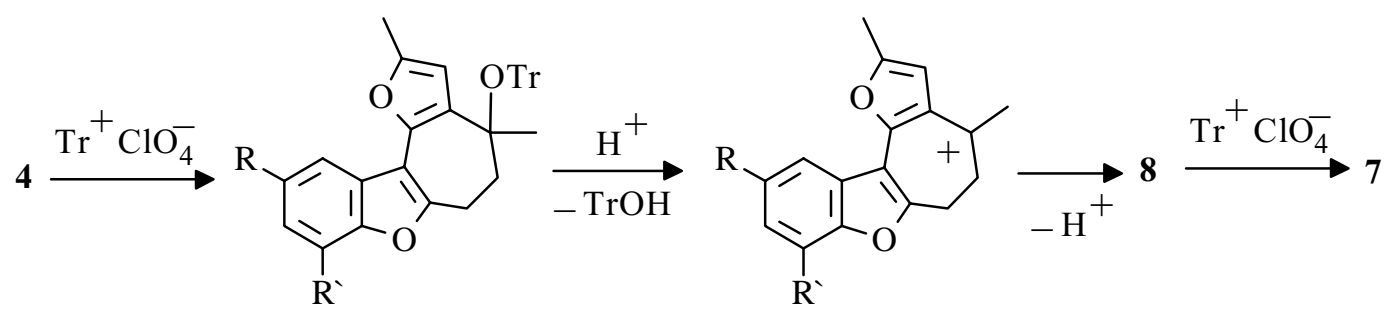

\section{Scheme 8.}

It is of interest that this reaction pathway is in contrast to that reported for 2hydroxytriphenylmethanole which gave 9-phenylxanthilium perchlorate under the treatment with tritylperchlorate [36]. In the case of 2-hydroxyaryldifurylmethane $\mathbf{3}$ apparently the transformation of preliminary formed 2-hydroxyarylbis(5-methylfur-2-yl)carbenium ions has happened (Scheme 9). 

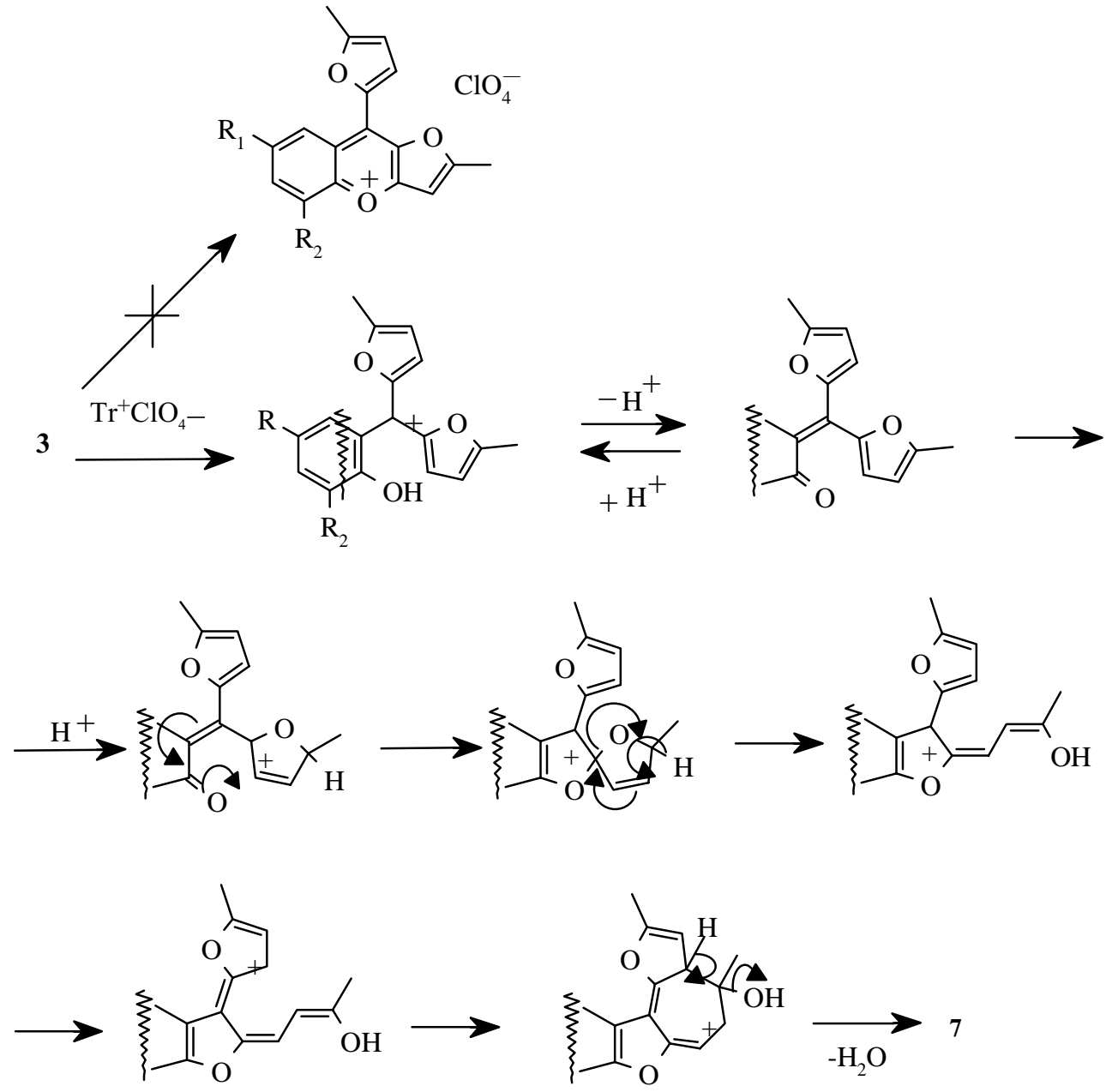

Scheme 9.<smiles>[R]c1cc([R])c2oc(CCC(C)=O)c(-c3ccc(C)o3)c2c1</smiles><smiles>[R]c1cc([R])c2oc3c(c2c1)-c1oc(C)cc1C(C)=CC3</smiles><smiles></smiles><smiles>[R]c1cc([R])c2oc3c(c2c1)-c1oc(C)cc1C(C)CC3</smiles>

Scheme 10. 
In our later work [37] it was reported, that refluxing of the benzofuran 4 with perchloric acid in dioxane results in the intramolecular cyclization and the subsequent disproportion of cycloheptatrienyl derivatives 8 to form perchlorates 7 and 5,6-dihydro-2,4-dimethyl-4H-benzo[b]furo[2,3-h]-1oxazulene derivatives 9 (Scheme 10).

To confirm the scheme of transformations cycloheptatriene derivatives $\mathbf{8}$ were obtained by the reduction of oxazulenium salts 7 with sodium borohydride (Scheme 11).
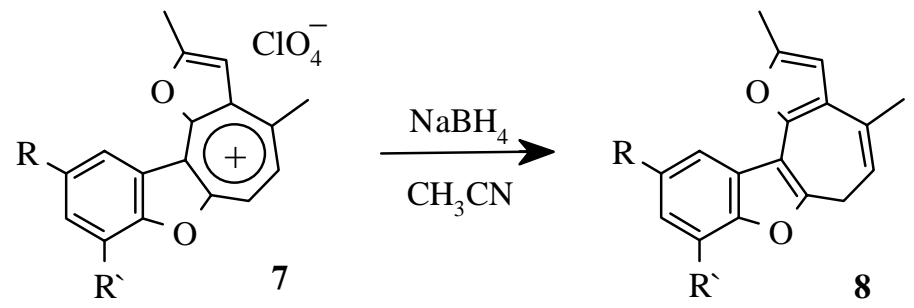

Scheme 11.

As expected, the compounds 8 proved to be rather sensitive to air oxygen, darkened at the storage at room temperature and easily formed the appropriate salts 7 with tritylperchlorate. The intermediate formation of the dihydrocompounds 8 in the above menthioned reaction (Scheme 10) was proved by their direct transformation into a mixture of compounds 7 and 9 under the action of equimolar quantities of perchloric acid.

We showed that it is possible to obtain perchlorate 7 directly from salicylic aldehydes 1 and 2methylfuran 2 by refluxing them in dioxane with perchloric acid.

Dihydroderivatives 9 were obtained by counter synthesis by reduction of appropriate benzofuran ketones to secondary alkohols with the subsequent intramolecular cyclization in the presence of sulfuric acid (Scheme 12) [37].<smiles></smiles>

Scheme 12.

Aromatic analogues of compounds 5 were synthesized by phosphoric acid catalysed cyclization of tertiary alkohols resulted from treatment of benzofurans 4 with corresponding arylmagnesium bromides as shown on the Scheme 13. 


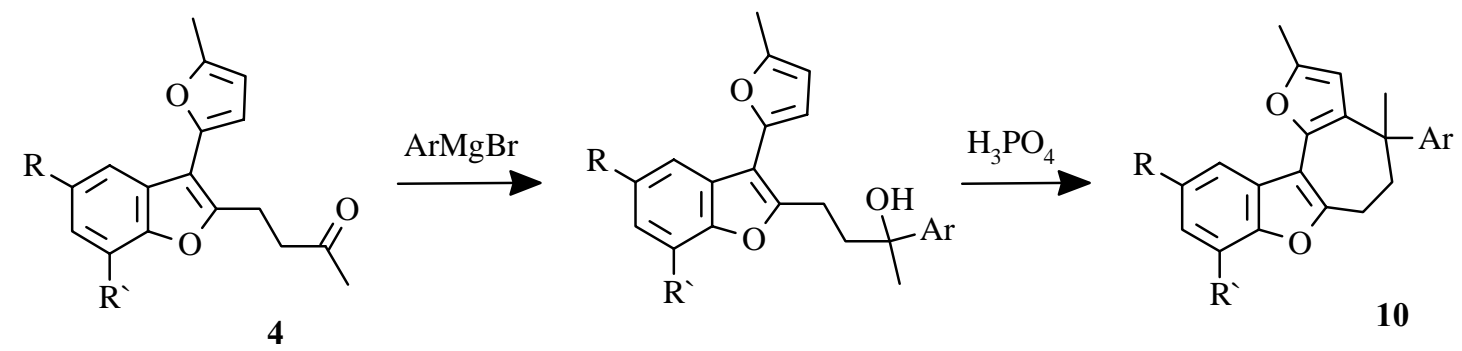

Scheme 13. Ar = phenyl; p-anisyl; o-anisyl.

Thus, starting from the compounds $\mathbf{1}$ and $\mathbf{2}$, it is possible to obtain 2-hydroxyaryldifurylmethanes $\mathbf{3}$, benzofurans 4 or oxazulene derivatives 7, 9 with high selectivity by simple change of the catalyst and solvent.

\section{References and Notes}

1. Boufi, S.; Gandini, A.; Belgacem, M. Polymer 1995, 36, 1689.

2. Stanford, J. L.; Still, R. H.; Cawse, J. L. GB Pat. 2116166. 1983.

3. Nowakowski, J. Polish Pat. 148406. 1990.

4. Sanderson, R. D.; Schneider, D. F.; Schreuder, I. J. Appl. Polym. Sci. 1995, 55, 1837.

5. Dunlop, A. P.; Eftax, D. S. P. U. S. Pat. 3287374. 1966.

6. Gandini, A.; Salon, M. C. Eur. Pat. 379250. 1990.

7. Lesimple, A.; Le Bigot, Y.; Delmas, M.; Gaset, A.; Roux, G. Fr. Pat. 9302072.1993.

8. He, X.; Conner, A. H.; Koutsky, J. A. J. Polym. Sci., Part A: Polym. Chem. 1992, 30, 533.

9. Cawse, J. L.; Stanford, J. L.; Still, R. H. Makromol. Chem. 1984, 185, 709.

10. Boufi, S.; Belgacem, M. N.; Quillerou, J.; Gandini, A. Macromolecules 1993, 26, 6706.

11. Shulezhko, A. A.; Rozhdestvenskaya, I. T.; Kiprianov, A. I. Zh. Org. Khim. 1970, 6, 2118.

12. Fukuda, M.; Fukunishi, A.; Mori, M. Jap. Pat. 06171214. 1994.

13. Musau, R. M.; Whiting, A. J. Chem. Soc., Perkin Trans. 1 1994, 2881.

14. He, Y.; Chen, Z.; Wu, C. Hecheng Huaxue 1993, 1, 123.

15. Stoll, M.; Winter, M.; Gautschi, F.; Flament, I.; Willhalm, B. Helv. Chim. Acta 1967, 50, 628.

16. Salinas, J. P.; Hartman, T. G.; Karmas, K.; Lech, J.; Rosen, R. T. ACS Symp. Ser. 1994, 558(Lipids in Food Flavors), 108.

17. Pons, I.; Garrault, C.; Jaubert, J. N.; Morel, J.; Fenyo, J. C. Food Chem. 1991, 39, 311.

18. Frattini, C.; Bicchi, C.; Barettini, C.; Nano, G. M. J. Agric. Food Chem. 1977, 25, 1238.

19. Nakanishi, M.; Mukai, T.; Inamasu, S. Jap. Pat. 44027990. 1969.

20. Dean F. M. Advan. Heterocycl. Chem. 1982, 30, 167.

21. Dean F. M. Advan. Heterocycl. Chem. 1982, 31, 237.

22. Jones, G.; McKinley, W. H. Tetrahedron Lett. 1977, 2457

23. Jones, G.; McKinley, W. H. J. Chem. Soc., Perkin Trans. 1. 1979. 599. 
24. D'Auria, M.; D'Onofrio, F.; Piancatelli, G. Gazz. Chim. Ital. 1994. 124, 125.

25. Butin, A. V.; Abaev, V. T.; Stroganova, T. A.; Gutnov, A. V. Molecules 1997, 2, 62.

26. Butin, A. V.; Abaev, V. T.; Stroganova, T. A. Khim. Geterotsikl. Soedin. 1995, 1578.

27. Butin, A. V.; Stroganova, T. A.; Abaev, V. T.; Zavodnik, V. E. Khim. Geterotsikl. Soedin. 1997, 1614.

28. Butin, A. V.; Zavodnik, V. E.; Kul'nevich, V. G. Khim. Geterotsikl. Soedin. 1992, 997.

29. Butin, A. V.; Krapivin, G. D.; Zavodnik, V. E.; Kul'nevich, V. G. Khim. Geterotsikl. Soedin. 1993, 616.

30. Riad, A.; Mouloungui, Z.; Delmas, M.; Gaset, A. Synth. Commun. 1989, 19, 3169.

31. Gutnov, A. V.; Abaev, V. T.; Butin, A. V.; Zavodnik, V. E.; Kul'nevich, V. G. Khim. Geterotsikl. Soedin. 1996, 162.

32. Butin, A. V.; Kul'nevich, V. G. Khim. Geterotsikl. Soedin. 1992, 566.

33. Butin, A. V.; Stroganova, T. A.; Kul'nevich, V. G. Khim. Geterotsikl. Soedin. 1996, 175.

34. Abaev, V. T.; Gutnov, A. V. ; Butin, A. V. Khim. Geterotsikl. Soedin. 1998, 603.

35. Butin, A. V.; Abaev, V. T.; Zavodnik, V. E.; Kul'nevich, V. G. Khim. Geterotsikl. Soedin. 1993, 627.

36. Luk'ianov, S. M.; Etmetchenko, L. N.; Dorofeenko, G. N. Zhurn. Org. Khim. 1978, 14, 399.

37. Butin, A. V.; Gutnov, A. V.; T. A Abaev, V. T.; Krapivin, G. D. Khim. Geterotsikl. Soedin. 1998, 883.

Samples Availability: Available from MDPI.

(C) 1999 by Molecular Diversity Preservation International (MDPI) 